\title{
PENGEMBANGAN BAHAN AJAR REALISTIK PADA POKOK BAHASAN PERBANDINGAN UNTUK SISWA SMP KELAS VII
}

\author{
Rofiroh \\ Teknik Mesin, Fakultas Teknik, Universitas Muhammadiyah Tangerang, \\ Jalan Perintis Kemerdekaan I No.33 Cikokol, Babakan, Tangerang, Banten, 15118 \\ e-mail: rofiroh@gmail.com
}

\begin{abstract}
Abstrak
Penelitian ini bertujuan untuk menghasilkan bahan ajar dengan pendekatan realistik yang dapat digunakan secara mandiri oleh siswa. Penelitian ini menggunakan metode Research and Development (R\&D) yang meliputi studi pendahuluan, pengembangan draft, uji coba dan pengembangan produk akhir. Draft dikembangkan dengan cara desain produk, validasi desain, revisi desain, uji coba produk dan revisi produk. Draft divalidasi oleh dua ahli ahli pendidikan dan ahli matematika. Uji coba skala kecil dilakukan terhadap 8 orang siswa kelas VII dan kelas VIII siswa SMPN 4 Pandeglang. Kesimpulan yang diperoleh dari hasil uji coba skala kecil yaitu mendapat respon yang positif dari siswa dengan total persentase akhir angket sebesar $90 \%$. Berdasarkan hasil validasi ahli dan uji coba terbatas didapatkan hasil bahwa bahan ajar dengan pendekatan realistik layak digunakan untuk membantu kegiatan belajar mengajar.
\end{abstract}

Kata Kunci: Bahan Ajar, Perbandingan, Pendekatan Realistik.

\begin{abstract}
This study aims to produce teaching materials with a realistic approach that can be used independently by students. This study used the Research and Development (R \& D) method which included preliminary studies, draft development, trials and final product development. The draft was developed by means of product design, design validation, design revision, product testing and product revision. The draft was validated by two experts in education and mathematicians. Small-scale trials were carried out on 8 students of $7^{\text {th }}$ and $8^{\text {th }}$ grade of SMP 4 Pandeglang. The conclusion obtained from the results of those trials shows that the approach gets positive responses from students with a final total percentage of $90 \%$ from the questionnaires. Based on the results of expert validation and limited trials, it has been found that teaching materials with realistic approaches are feasible to be used to assist teaching and learning activities.
\end{abstract}

Keywords: Teaching Material, Comparison, Realistic Approach.

\section{PENDAHULUAN}

Sejak tahun 1973 di Indonesia, pelajaran matematika diberikan mulai dari sekolah dasar, menengah pertama dan menengah atas (Zakaria, 2017). Menurut Arsaythamby (2014), proses pembelajaran matematika di Indonesia khususnya di Aceh masih berlangsung secara konvesional dan berpusat pada guru.

Fenomena tersebut menunjukan bahwa proses pembelajaran matematika yang dilakukan di kelas berupa menjelaskan konsep dan memberi contoh soal berdasarkan konsep. Kemudian, soal yang serupa dengan contoh diselesaikan oleh siswa. Diakhiri dengan siswa diberikan latihan soal berupa variasi soal yang serupa dengan contoh sampai aplikasi matematika dalam kehidupan sehari-hari. 
Menurut Arsaythamby (2014) dan Asih (2018), seharusnya guru memiliki kemampuan untuk mengaktifkan peserta didik. Selain itu, guru bertugas merancang pembelajaran yang bermakna bagi peserta didik dengan mengembangkan bahan ajar matematika.

Berdasarkan Permendiknas Nomor 16 Tahun 2007 tentang Standar Kualifikasi Akademik dan Kompetensi Guru bagian B, guru sebagai pendidik profesional diharapkan memiliki kemampuan mengembangkan bahan ajar. Pengembangan Bahan ajar dirancang dengan memperhatikan karakteristik dan lingkungan sosial peserta didik (Reza Anwari, 2017).

Bahan ajar diharapkan dapat mengatasi keabstrakan siswa terhadap matematika. Menurut Rizki, W (2018) bahan ajar dirancang dengan tujuan untuk mengatasi atau mengurangi learning obstacle yang muncul agar peserta didik mampu memahami konsep suatu materi dalam matematika secara utuh.

Sifat abstrak matematika dapat diatasi dengan menerapkan pendekatan realistik pada bahan ajar matematika. Pendekatan realistik pertama kali dikenalkan di Belanda. Ide pendekatan realistik berasal dari Freudenthal yang mengatakan bahwa matematika adalah aktivitas manusia. Aktivitas tersebut dilihat sebagai proses dari belajar matematika (Zakaria, 2017).

Proses pembelajaran matematika dapat diawali dengan mengilustrasikan konsep-konsep matematika dan masalah kontekstual. Selain itu, guru harus mengilustrasikan dengan pengalaman siswa dalam kehidupan sehari-hari. Kemudian, siswa diharuskan untuk menerapkan kembali konsep matematika yang telah dimiliki siswa pada kehidupan seharihari.

Penelitian yang dilakukan oleh Zakaria dengan judul "The Effect of Realistic Mathematics Education Approach on Students' Achievement and Attitudes Toward Mathematics". Hasil penelitian menunjukan bahwa pada 61 siswa di SMA Unggul Sigli menemukan bahwa matematika penggunaan pendekatan pendidikan matematika realistis meningkatkan prestasi matematika siswa, tetapi bukan sikap terhadap matematika. Pendekatan Pendidikan Matematika Realistis mendorong siswa untuk berpartisipasi aktif dalam pengajaran dan pembelajaran matematika. Dengan demikian, Pendekatan realistik adalah metode yang tepat untuk meningkatkan kualitas proses belajar mengajar matematika. (Zakaria, 2017).

Penelitian yang dilakukan oleh Arsaythamby dengan judul "How A Realistic Mathematics Educational Approach Affect Students' Activities In Primary Schools?". Hasil

Prima, Vol. 3, No. 1, Januari 2019, 1-8. 
penelitian menunjukan bahwa pengajaran dan pembelajaran matematika di Aceh dengan pendekatan realistik mengaktifkan siswa di kelas. (Arsaythamby, 2014).

Penelitian yang dilakukan oleh Wayan dengan judul "Komparasi Kemampuan Pemecahan Masalah Matematika antara PMR dan PBM Materi Geometri SMP Kelas “. Hasil penelitian siswa kelas VII non unggulan di SMP N 1 Sukasada pada tahun ajaran 2017/2018 menunjukan bahwa kemampuan pemecahan masalah matematika siswa yang dibelajarkan dengan pembelajaran matematika realistik lebih baik daripada kemampuan pemecahan masalah matematika siswa yang dibelajarkan dengan pembelajaran berbasis masalah. (Wayan 2018).

Berdasarkan kondisi tersebut, perlu adanya pengembangan bahan ajar yang dikembangkan dengan pendekatan realistik yang diadopsi langsung dari Realistic Mathematics Education (RME). Peneliti akan melakukan penelitian yag berjudul "Pengembangan Bahan Ajar Realistik pada Pokok Bahasan Perbandingan untuk Siswa SMP Kelas VII". Manfaat dari penelitian ini adalah menghasilkan bahan ajar realistik yang dapat digunakan baik oleh guru atau siswa terkait dengan pembelajaran sehingga siswa mampu mengilustrasikan dan menerapkan kembali konsep matematika di kehidupan sehari-hari.

\section{METODE PENELITIAN}

Metode yang digunakan dalam penelitian adalah penelitian pengembangan (development research) dengan tujuan menghasilkan suatu produk berupa bahan ajar realistik. Model pengembangan bahan ajar yang akan digunakan dalam penelitian ini adalah dengan model pengembangan 4D. Menurut Riski (2015), pemilihan model pengembangan 4D dikarenakan model tersebut yang disarankan dalam pengembangan perangkat pembelajaran.Model tersebut diadopsi dari Thiagarajan, S. Semmel, D.S \& Semmel, MI, yang meliputi 4 tahap yaitu: define, design, develop dan disseminate (Asih, 2018). Alur pengembangan bahan ajar yang dilakukan peneliti disajikan pada Gambar 1 berikut. 


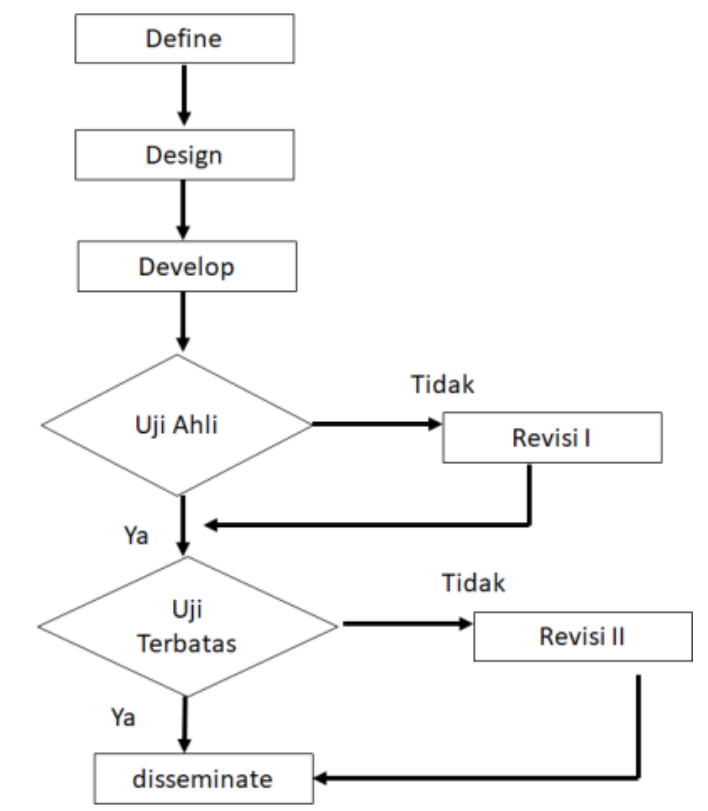

Gambar 1. Diagram Alur Pengembangan.

Instrumen penelitian pengembangan ini menggunakan instrumen angket. Angket sebagai alat untuk mengukur bahan ajar yang dikembangkan layak untuk digunakan. Angket terdiri dari angket ahli dan angket siswa.

Skor yang diperoleh pada angket responden merupakan data angket. Data tersebut diolah dengan menggunakan skala likert. Setiap responden diminta untuk menjawab pertanyaan pada angket dengan jawaban Sangat Setuju (SS), Setuju (S), Tidak Setuju (TS) dan Sangat Tidak Setuju (STS). Pernyataan baik positif maupun maupun negatif diterapkan skor seperti tampak pada Tabel 1.

Tabel 1. Penetapan Skor Angket

\begin{tabular}{ccccc}
\hline Pernyataan & $\begin{array}{c}\text { Sangat Setuju } \\
\text { (SS) }\end{array}$ & Setuju (S) & $\begin{array}{c}\text { Tidak Setuju } \\
\text { (TS) }\end{array}$ & $\begin{array}{c}\text { Sangat Tidak } \\
\text { Setuj sku (STS) }\end{array}$ \\
\hline $\begin{array}{c}\text { Pernyataan } \\
\text { Positif }\end{array}$ & 4 & 3 & 2 & 1 \\
\hline $\begin{array}{c}\text { Pernyataan } \\
\text { Negatif }\end{array}$ & 1 & 2 & 3 & 4 \\
\hline
\end{tabular}

Hasil data angket responden dideskripsikan dengan menggunakan rumus berikut :

$$
p=\frac{\text { skor mentah }}{\text { skor ideal }} \times 100 \%
$$

dengan skor mentah dan skor ideal diperoleh dari jumlah skor jawaban responden dan jumlah skor jawaban tertinggi. Menurut Ridwan (2013), hasil presentasi angket dapat diinterpretasi dengan kategori persentase berdasarkan kriteria klasifikasi skala yang disajikan pada Tabel 2.

Prima, Vol. 3, No. 1, Januari 2019, 1-8. 
Tabel 2. Kriteria Interpretasi Skor Skala Angket

\begin{tabular}{cc}
\hline Kriteria & Klasifikasi \\
\hline $0 \% \leq p \leq 20 \%$ & Sangat lemah \\
$20 \% \leq p \leq 40 \%$ & Lemah \\
$40 \% \leq p \leq 60 \%$ & Cukup \\
$60 \% \leq p \leq 80 \%$ & Baik \\
$80 \% \leq p \leq 100 \%$ & Sangat baik \\
\hline
\end{tabular}

\section{HASIL DAN PEMBAHASAN}

Bahan ajar realistik dikembangkan agar siswa memahami, menjelaskan dan menyelesaikan masalah kontekstual. Bahan ajar juga dirancang agar siswa dapat mendiskusikan jawaban menyimpulkan akhir dari dari proses pembelajaran.

Bahan ajar dalam penelitian ini berupa bahan ajar dengan pendekatan realistik pada bab perbandingan untuk siswa sekolah menengah pertama. Bahan ajar realistik terdiri dari 4 bab. Bab-bab tersebut yaitu: Bab 1 adalah Pengenalan Materi Perbandingan, Bab 2 adalah Gambar Berskala, Bab 3 bentuk-bentuk perbandingan, dan Bab 4 adalah Memecahkan Masalah Sehari-hari yang Melibatkan Perbandingan.Bab tersebut memuat subbab. Bab 1 memuat subab pengertian perbandingan, menyederhanakan perbandingan dua besaran sejenis dan hubungan perbandingan dan pecahan. Bab 2 memuat subbab peta dan faktor skala pada gambar. Bab 3 memuat subbab perbandingan senilai, perbnadingan berbalik nilai dan menggambar grafik perbandingan. Bab 4 memuat subbab latihan soal memcahkan masalah sehari-hari yang berhubungan dengan perbandingan.

Tampilan bahan ajar ini diawali dengan cover, kata pengantar, panduan buku, daftar isi. Berikut adalah tampilan bahan ajar. 

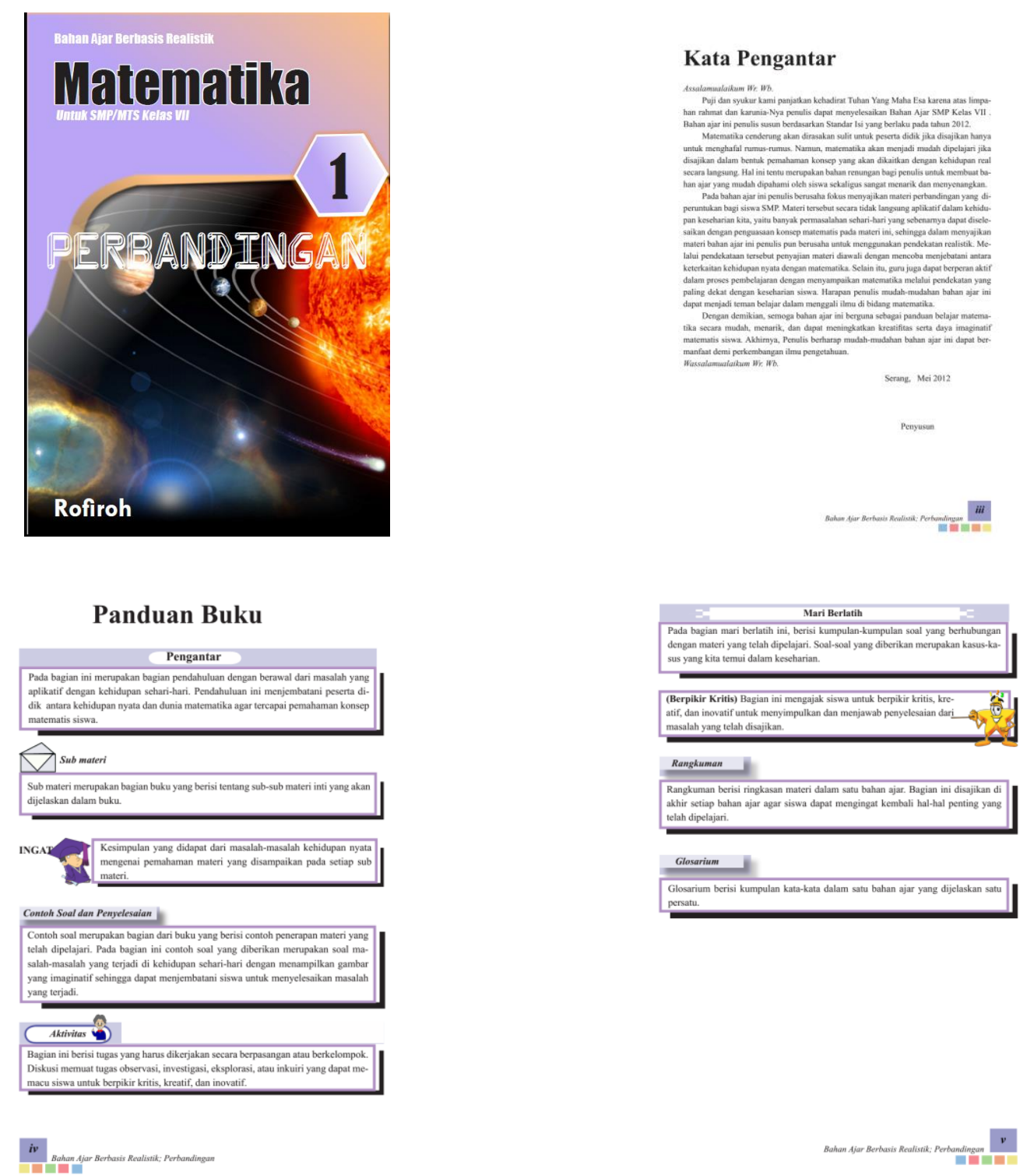

\section{Gambar 2. Tampilan Bahan Ajar Realistik}

Langkah selanjutnya setelah bahan ajar selesai dikembangkan adalah menguji bahan ajar tersebut kepada ahli pendidikan.

Tabel 3. Hasil Angket Uji Ahli

\begin{tabular}{ccc}
\hline Uji & Presentase & Klasifikasi \\
\hline Ahli pendidikan matematika & $81 \%$ & Baik \\
Ahli matematika & $80 \%$ & Baik \\
& &
\end{tabular}

Berdasarkan uji ahli pendidikan matematika bahan ajar ini sangat baik dan menarik, penyampaian materi dari aspek keakuratan konsep dan lebih realistik dengan kehidupan sehari-hari. Ahli pendidikan matematika juga menambahkan keakiratan gambar, notasi, simbol dan icon tidak terkesan monoton menampilkan rumus-rumus matematika yang kurang 
disukai siswa SMP. Saran ahli pendidikan matematika adalah bahan ajar ini siap digunakan untuk siswa menengah pertama dan dikembangkan kembali untuk pokok bahasan yang lain.

Setelah dilakukan uji ahli dan perbaikan produk bahan ajar, kemudian dilakukan uji coba produk terhadap kelompok kecil (uji terbatas). Uji kelompok kecil terdiri dari 8 orang siswa dari SMP Negeri 4 Pandeglang. Siswa diperkenalkan terlebih dahulu bahan ajar realistik. Siswa diberi kesempatan untuk mempelajari bahan ajar realistik.

Titik awal belajar matematika pada bahan ajar ini adalah masalah kontekstual, dimana siswa berdiskusi dalam satu kelompok tentang masalah kontekstual dari isi bahan ajar realistik. Kegiatan ini memicu siswa saling timbal balik memberikan informasi apa yang mereka ketahui tentang bahan ajar realistik. Tahap ini juga bertujuan agar kedelapan siswa ikut terlibat dalam setiap aktivitas yang disajikan dalam bahan ajar tersebut. Berdasarkan pengamatan, aktivitas siswa menjadi aktif $90 \%$.

\section{SIMPULAN DAN SARAN}

Berdasarkan penelitian dan pengembangan diperoleh kesimpulan bahwa bahan ajar realistik pada materi perbandingan dapat digunakan oleh siswa menengah pertama. Adapun saran untuk bahan ajar realistik agar dikembangkan pada pokok bahasan yang lain. Selain itu, ditambahkan latihan soal yang variatif dan berhubungan untuk membantu mengembangkan kemampuan kognitif siswa siswa. Hal lain yang harus diperhatikan juga bahwa pembelajaran menggunakan bahan ajar realistik harus dilakukan pada saat jam pelajaran atau tidak pada kondisi yang terburu-buru.

\section{DAFTAR PUSTAKA}

Anwari, R. (2017). Desain Didaktis Interaktif Problem Solving Matematis Pada Pokok Bahasan Kesebangunan, Jurnal Penelitian Pembelajaran Matematika, Vol 10 (1), pp:69.

Arsaythamby dan Zubainur, C.M. (2014): How A Realistic Mathematics Educational Approach Affect Students' Activities In Primary Schools?, Jurnal of Procedia - Social and Behavioral Sciences, Vol 159, pp:309-313.

Asih, I.V.Y., dkk. (2018). Pengembangan Bahan Ajar Terstruktur untuk Meningkatkan Keterampilan Mahasiswa dalam Merancang Media Hands on Activity Serta Lembar Kerja Eksploratif Pendamping, Jurnal Penelitian Matematika, Vol 11 (1). Tersedia pada : http://jurnal.untirta.ac.id/index.php/JPPM/article/view/2983/2314. 
Riduwan. (2013). Dasar-dasar statistika. Bandung: Alfabeta.

Rizki, S. (2015). Pengembangan Bahan Ajar Program Linear Berbasis Konstektual dan ICT. Jurnal Pendidikan Matematika FKIP Univ.Muhamadiyah Metro, Vol 5 (2). Tersedia pada : http://ojs.fkip.ummetro.ac.id/index.php/matematika/article/view/674V.

Wahyu, R. P., dan Setiwati, N. (2018). Pengembangan Desain Didaktis Bahan Ajar Persamaan Garis Lurus, Jurnal Penelitian Pendidikan Matematika, Vol.11(1). Tersedia pada : pada : http://jurnal.untirta.ac.id/index.php/JPPM/article/view/2992.

Wayan, I. A., dkk. (2018). Komparasi Kemampuan Pemecahan Masa Matematika antara PMR dan PBM Materi Geometri SMP Kelas VII, Jurnal Pendidikan Matematika dan Matematika, Vol 1 (4), pp: 47-60.

Zakaria, E., dan Syamaun, M. (2017): The Effect of Realistic Mathematics Education Approach on Students' Achievement and Attitudes Toward Mathematics, Jurnal of Mathematics Education Trends and Research, Vol, pp:32-40.

Prima, Vol. 3, No. 1, Januari 2019, 1-8. 